\title{
Investigating dysautonomia of Bradbury Eggleston syndrome: A case report
}

\author{
Soumayata Somendra' ${ }^{1}$ Amit Tak' ${ }^{2}$, Jyotsna Shukla ${ }^{3}$, Kapil Gupta ${ }^{3}$, Jitendra Gupta ${ }^{3}$ \\ ${ }^{1}$ SMS Medical College and attached Hospitals, Jaipur, Rajasthan, India \\ ${ }^{2}$ National Centre for Disease Informatics and Research, Bengaluru, Karnataka, India \\ ${ }^{3}$ Department of Physiology, SMS Medical College and attached Hospitals, Jaipur, Rajasthan, India
}

\begin{abstract}
This is a report of 65 years old man with recurrent episodes of dizziness while standing from supine position and history of constipation and nocturia since last 6 months. Patient disclosed no significant past history other than treated pulmonary tuberculosis 5 years back. The general mental state and vital parameters were within normal limits. Autonomic function tests and heart rate variability analysis measured autonomic reactivity and tone respectively. The tests revealed that autonomic dysfunction include severe sympathetic and mild parasympathetic involvement. After exclusion of other possible causes of orthostatic hypertension, diagnosis of pure autonomic failure also known as Bradbury Eggleston syndrome was established. Treatment with fludrocortisones and non-pharmacological interventions improved orthostatic tolerance.
\end{abstract}

Keywords: autonomic function tests, Bradbury Eggleston syndrome, heart rate variability, pure autonomic failure, sympathetic impairment

\section{INTRODUCTION}

Dysautonomia is a condition characterized by orthostatic hypotension $(\mathrm{OH})$, anhidrosis, impotence, sleep dysfunction, constipation and other gastro-intestinal symptoms [1]. It occurs secondary to neurodegenerative diseases, diabetes mellitus, amyloidosis and malignancy. Pure Autonomic Failure (PAF) is an adult onset, progressive primary neurologic disorder of the autonomic nervous system and must be considered in the differential diagnosis of orthostatic hypotension [2]. Most adolescent patients with primary autonomic orthostatic hypotension have multiple system atrophy or PAF (Bradbury-Eggleston syndrome) [3,4]. In this report we investigated an unusual case of orthostatic hypertension and establish diagnosis of PAF from exclusion and discussed role of autonomic function tests and heart rate variability in early diagnosis of the disease.

\section{CASE PRESENTATION}

The authors have obtained all appropriate patient consent forms to be reported in the journal. A 65 years old man reported recurrent episodes of dizziness while standing from supine position and on prolonged standing. He has constipation and nocturia since 5 months. Past history revealed cured pulmonary tuberculosis 5 years back. He gave no history of hypertension, diabetes mellitus, thyroid disorder, weight loss and surgery. The patient was a chronic smoker but no addictive history. On general examination, patient was conscious, cooperative and well oriented. The blood pressure (BP) was 130/80 $\mathrm{mmHg}$ with pulse rate of $60 \mathrm{bpm}$ in supine position. The respiratory rate was 14 breaths per minute. The general examination was unconvincing. 
The systemic examination was apparently normal. The autonomic assessment was performed with baseline heart rate of $58 \mathrm{bpm}$. The BP was monitored in both arms with 130/80, 90/56 and $88 / 60 \mathrm{~mm} \mathrm{Hg}$ in supine position, immediately after standing and after 3 minutes respectively. The fall in systolic and diastolic BP after 3 minutes was 42 $\mathrm{mmHg}$ and $20 \mathrm{mmHg}$ respectively. In addition, the pulse rates were 60,64 and $65 \mathrm{bpm}$ in supine position, immediately after standing and after $3 \mathrm{~min}$ utes respectively.

To exclude the differential causes of autonomic failure complete blood count with erythrocyte sedimentation rate, random blood glucose, serum electrolytes, liver function tests, urea, creatinine and vitamin $\mathrm{B}_{12}$ were done. Imaging tests include chest $\mathrm{X}$-ray, chest CT, USG of abdomen and MRI brain. The electrocardiography and nerve conduction studies were done. The cardiovascular autonomic reactivity assessment were performed according to Ewing's battery of tests using CANWIN (cardiac autonomic neuropathy analyzer) machine [5]. The cardiovascular reactivity for parasympathetic arm was assessed with expiration-inspiration ratio (E:I ratio) while deep breathing, 30:15 ratio in supine to standing position, and Valsalva ratio. The sympathetic function was assessed with isometric hand grip test. The baseline blood pressure was recorded followed by measurement at 30 seconds, 1 minute and 2 minutes after release of handgrip (Table 1). The heart rate variability is used to assess tone of autonomic system in various diseases [6]. Electrocardiographic data in supine position for 5 minutes was acquired following standardized protocols [7]. A tachogram of RR intervals was plotted with the help of RMS software (Figure 1). The analysis was carried out with the help of HRV Kubois software. The time domain measures include mean RR, SDNN, RMSDD and pNN50, while frequency domain measures include LF/HF ratio. In Poincare plot, SD1 > SD2 reflects autonomic variability. The details can be found in Electrophysiology Task Force, 1996 [7]. The results were compared with normal values estimated by Acharya et al. [8].
TABLE 1. Results of autonomic function tests for evaluation of parasympathetic and sympathetic components [5]

\begin{tabular}{|c|c|c|c|}
\hline $\begin{array}{l}\text { Autonomic } \\
\text { components }\end{array}$ & Tests & Results & Normal Range \\
\hline \multirow[t]{3}{*}{ Parasympathetic } & $\begin{array}{l}\text { Deep breathing } \\
\text { (E:I ratio) }\end{array}$ & 1.09 & $\geq \geq 1.21$ \\
\hline & $\begin{array}{l}\text { Response to } \\
\text { standing (30:15 } \\
\text { ratio) }\end{array}$ & 1.00 & $\geq \geq 1.04$ \\
\hline & Valsalva ratio & 6.67 & $\geq \geq 1.21$ \\
\hline Sympathetic & $\begin{array}{l}\text { Sustained } \\
\text { Hand grip Test } \\
\text { (Increase in DBP) }\end{array}$ & $\begin{array}{l}5 \\
\mathrm{mmHg}\end{array}$ & $\geq \geq 16 \mathrm{mmHg}$ \\
\hline
\end{tabular}

\section{DISCUSSION}

Orthostatic hypertension $(\mathrm{OH})$ is defined as sustained drop in systolic and diastolic blood pressure of $\geq \geq 20 \mathrm{~mm} \mathrm{Hg}$ and $\geq \geq 10 \mathrm{~mm} \mathrm{Hg}$ respectively after 3 minutes of standing [1]. Orthostatic hypertension can be one of the features of neurodegenerative diseases, various nutritional, autoimmune, drug or metabolic disturbances [9]. PAF is a rare primary neurodegenerative disorder characterized by severe sympathetic dysfunction with or without mild parasympathetic involvement and affects women predominantly in midlife. The diagnosis of PAF is based on exclusion[10], it is a type of synucleinopathy causing accumulation of misfolded alpha-synuclein in the intermediate lateral tract of medulla and in the sympathetic ganglia.

The clinical symptoms and changes in systolic and diastolic BP from supine to standing position were 42 and $20 \mathrm{~mm} \mathrm{Hg}$ respectively and suggestive of $\mathrm{OH}$. The compensatory pulse rate of $5 \mathrm{bpm}$ favors neurogenic $\mathrm{OH}$. The history was non-significant. The normal levels of blood glucose and glycated hemoglobin rule out diabetic neuropathy. The renal function tests and USG suggests no renal involvement. The addition's disease and sarcoidosis was rule out based on normal electrolytes and liver function tests respectively. The vitamin $\mathrm{B}_{12}$ levels were within limits. Normal thyroid function tests, serum cortisol and ACTH rule out thyroid and adrenal pathologies. Anti-nuclear antibody by indirect

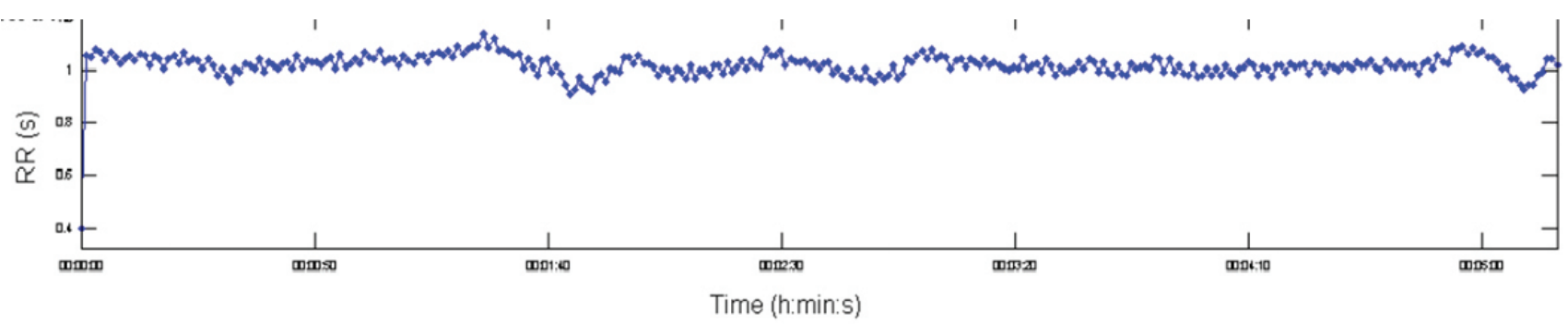

FIGURE 1. Tachogram. A series of RR intervals calculated from electrocardiographic recording obtained for 5 minutes were plotted 
TABLE 2. Time and frequency domain measures along with Poincare plot measures of patient. The normal values are shown as calculated by Acharya et al. (2004) [8]

\begin{tabular}{|c|c|c|c|}
\hline & Description & Values & $\begin{array}{l}\text { Normal Range at } \\
\text { age } 65 \text { years* }\end{array}$ \\
\hline \multicolumn{4}{|l|}{ Time domain measures } \\
\hline Mean RR (SD) (ms) & mean of RR intervals & 1017.9 & \\
\hline SDNN (ms) & standard deviation of RR interval & 48.5 & 70.89 \\
\hline RMSSD (ms) & square root of the mean squared differences of successive RR intervals & 46.2 & 78.43 \\
\hline pNN50 (\%) & $\begin{array}{l}\text { the proportion derived by dividing number of interval differences of } \\
\text { successive RR intervals greater than } 50 \text { ms by the total number of RR } \\
\text { intervals }\end{array}$ & 3.5 & 9.77 \\
\hline \multicolumn{4}{|c|}{ Frequency domain measures } \\
\hline 5-min Total power $\left(\mathrm{ms}^{2}\right)$ & variance of RR intervals & 1454 & \\
\hline $\operatorname{LF}\left(\mathrm{ms}^{2}\right)$ & power in low frequency range $(0.04-0.15 \mathrm{~Hz})$ & 179 & \\
\hline $\mathrm{HF}\left(\mathrm{ms}^{2}\right)$ & power in $\mathrm{HF}$ range $(0.15-0.4 \mathrm{~Hz})$ & 198 & \\
\hline LF/HF ratio & ratio of LF/HF & 0.904 & 1.57 \\
\hline \multicolumn{4}{|l|}{ Poincare plot measures } \\
\hline SD1 & $\begin{array}{l}\text { standard deviation along minor axis of imaginary ellipse, shown in figure } \\
2 .\end{array}$ & 32.7 & \\
\hline SD2 & $\begin{array}{l}\text { standard deviation along major axis of imaginary ellipse, shown in figure } \\
2 .\end{array}$ & 49.1 & \\
\hline SD1/SD2 & ratio of SD1 and SD2 & 0.66 & 0.60 \\
\hline
\end{tabular}

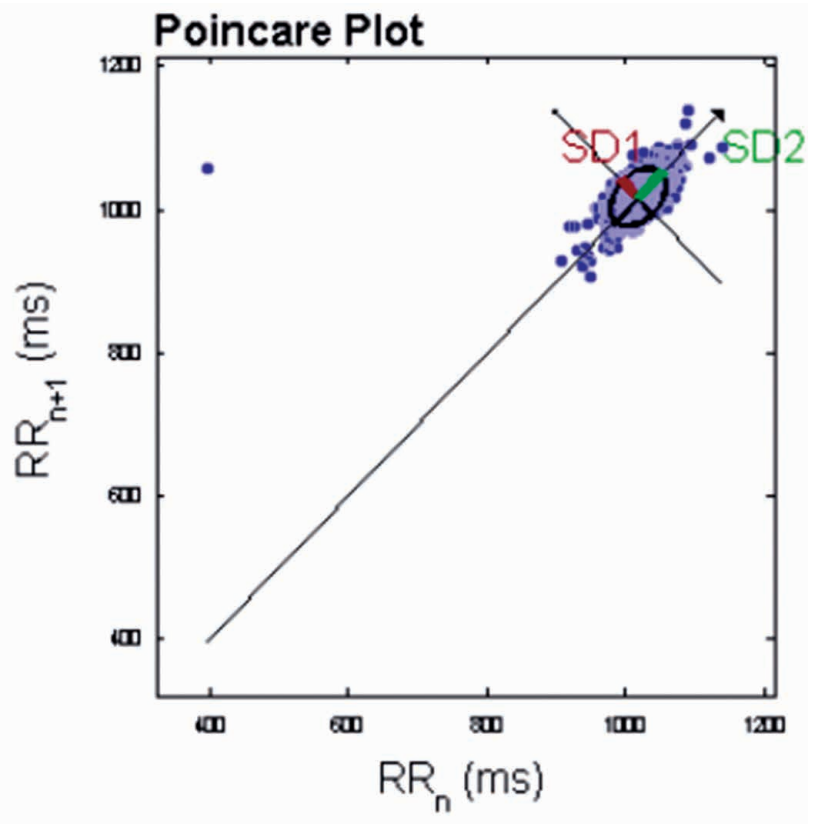

FIGURE 2. Poincare plot. The plot shows RR interval as a function of previous RR interval and SD1 and SD2 were minor and major axes of imaginary ellipse

fluorescent antibody method suggested no autoimmune association. Normal levels of serum calcium, carcinoembryonic antigen, alpha-feto-protein, and prostate specific antigen were against paraneoplastic syndrome. Chest X-ray and chest CT showed old calcification. Electrocardiogram showed normal sinus rhythm and 2D echocardiogram revealed no signs of cardiac failure. No signs of neurodegenerative diseases in MRI brain were seen.

The decreased E:I ratio and 30:15 ratio and increased in Valsalva ratio suggest mild parasympa- thetic dysfunction. In addition, limited change in diastolic pressure after 2 minutes during isometric hand grip test was suggestive of severe sympathetic dysfunction (Table 2).

The heart rate variability analysis showed decrease in SDNN, RMSSD, pNN50, suggestive of parasympathetic dysfunction. The decrease LF/HF ratio suggests major role sympathetic dysfunction. The Poincare plot analysis showed island pattern with SD1 < SD2, which suggests low autonomic variability [11].

The management includes non-pharmaceutical measures such as compressive stockings, cross leg maneuvers, gradual standing, increased liquid and salt intake, avoidance of prolonged orthostatism, alcohol and warm environment. The pharmacological measures include fludrocortisone (a mineralocorticoid) and midodrine (an alpha-adrenergic agonist). Although other drugs that are subject to ongoing trials include droxidopa, pyridostigmine and octreotide. The follow up of patient revealed lesser episodes of orthostatic hypotension, relieved constipation and occasional episodes of nocturia.

\section{CONCLUSIONS}

The pure autonomic failure is a rare primary disease of autonomic nervous system, but patients subsequently develop autoimmune autonomic gangliopathy, but more often a neurodegenerative diseases. The autonomic function tests and heart rate variability analysis helps in early diagnosis and investigation of disease process.

Conflict of interest: none declared Financial support: none declared 


\section{REFERENCES}

1. Jameson J, Fauci AS, Kasper DL, Hauser SL, Longo DL, Loscalzo J. eds. Harrison's Principles of Internal Medicine. New York, NY: McGraw-Hill; 2018.

2. Idiáquez J, Kaufmann H, Soza M, Necochea C. Falla auttonómica pura: Síndrome de Bradbury Eggleston. Revista médica de Chile. 2005 Feb;133(2):215-8.

3. Robertson D, Beck C, Gary T, Picklo M. Classification of autonomic disorders. International Angiology : a Journal of the International Union of Angiology. 1993 Jun;12(2):93-102.

4. The Consensus Committee of the American Autonomic Society and the American Academy of Neurology. Consensus statement on the definition of orthostatic hypotension, pure autonomic failure and multiple system atrophy. Neurology. 1996;46:1470.

5. Ewing DJ, Clarke BF. Diagnosis and management of diabetic autonomic neuropathy. Br Med J (Clin Res Ed). 1982 Oct 2;285(6346):916-8.

6. Tak A. A study of frequency domain analysis of heart rate variability in newly diagnosed hypertensives. JMSCR. 2019;7(8):459-63.
7. Heart rate variability: standards of measurement, physiological interpretation and clinical use. Task Force of the European Society of Cardiology and the North American Society of Pacing and Electrophysiology. Circulation. 1996 Mar 1;93(5):1043-65.

8. Acharya UR, Kannathal N, Sing OW, Ping LY, Chua T. Heart rate analysis in normal subjects of various age groups. Biomedical Engineering. 2004;3(1):24.

9. Robertson D, Mosqueda-Garcia R, Robertson RM, Biaggioni I. Chronic Hypotension: In the Shadow of Hypertension. American Journal of Hypertension. 1992;5(6):200-275.

10. Marouene $H$, Bellassoued M, Mnif M, et al. Pure primitive dysautonomia or Bradbury-Eggleston syndrome. Report of 3 cases. La Tunisie Medicale. 2001 Jun-Jul;79(6-7):383-388.

11. Ernst G. Heart rate variability. Chapter 4. Methodological Issues. Springer; 2014:56-57. 